\title{
Development of a new expendable probe for the study of pelagic ecosystems from voluntary observing ships
}

\author{
M. Marcelli ${ }^{1}$, A. Di Maio ${ }^{2}$, D. Donis ${ }^{1}$, U. Mainardi ${ }^{3}$, and G. M. R. Manzella ${ }^{4}$ \\ ${ }^{1}$ Departement DECOS, Tuscia University, Via S. Giovanni Decollato n. 1, 01100 Viterbo, Italy \\ ${ }^{2}$ AQSmare, Via del Molo di Levante, 1, 00054 Fiumicino (Roma), Italy \\ ${ }^{3}$ Maisoft, Via Ronchi n. 18, 24020 Villa di Serio (Bg), Italy \\ ${ }^{4}$ ENEA ACS, Forte S. Teresa, Loc. Pozzuolo, 19036 Lerici, Italy
}

Received: 9 August 2006 - Published in Ocean Sci. Discuss.: 11 September 2006

Revised: 10 January 2007 - Accepted: 18 March 2007 - Published: 4 June 2007

\begin{abstract}
Physical and biological processes of the marine ecosystem have a high spatial and temporal variability, whose study is possible only through high resolution and synoptic observations. The Temperature and Fluorescence Launchable Probe was charted in order to answer to the claim of a cost effective temperature and fluorescence expendable profiler, to be used in ships of opportunity. The development of the expendable fluorometer has followed similar concepts of the XBT (a wire conducting the signal to a computer card), but differently from the latter it was developed with an electronic system which can be improved and adapted to several variables measure channels. To reach the aim of a low-cost probe, were utilized commercial components: a glass bulb temperature resistor for the temperature measurement, blue LEDs, a photodiode and available selective glass filters, for the fluorescence measurement. The measurement principle employed to detect phytoplankton's biomass is the active fluorescence. This method is an in vivo chlorophyll estimation, that can get the immediate biophysical reaction of phytoplankton inside the aquatic environment; it is a non-disruptive method which gives real time estimation and avoids the implicit errors due to the manipulation of samples. The possibility of using a continuous profiling probe, with an active fluorescence measurement, is very important in real time phytoplankton's study; it is the best way to follow the variability of sea productivity. In fact, because of the high time and space variability of phytoplankton, due to its capability to answer in a relatively short time to ecological variations in its environment and because of its characteristic patchiness, there isn't a precise quantitative estimation of the biomass present in the Mediterranean Sea.
\end{abstract}

Correspondence to: M. Marcelli

(marcomarcell@tin.it)

\section{Introduction}

Operational forecasting of marine physical and biochemical state variables is becoming an important tool for modern management and protection of the oceans and their living resources. The forecasting systems need multidisciplinary input data, the operational collection of which is hampered by two main factors: cost and technology.

The methodology actually used for an operational monitoring of the oceans is mainly based on lagrangian profiling buoys (Argo) and on Ships Of Opportunities. Potentially, the Argo floats can measure physical, chemical and some biological parameters. In practice this potential capability is limited by cost and power supply. The Ships Of Opportunity Program (SOOP) is based on eXpendable BathyTermographs (XBT) technology developed at the end of 60's and provides only temperature profiles of the upper thermocline.

An operational observing and forecasting system for the physical properties of the ocean was set up in the Mediterranean Sea from 1999 (Pinardi et al., 2003) in the framework of an EC-supported pilot project. The project followup, called Mediterranean Forecasting System (MFS) - Toward Environmental Prediction (TEP), has implemented the forecasting system of the biological state variables. A Voluntary Observing Ship program (VOS) was devised, within the MFS-TEP project, to support ocean weather forecasting. The voluntary observing ships are essential, since are integrating ocean surface temperature from satellites, and contribute to the MFS capability of providing near real time analysis of the ocean state.

However, there is still a lack of basin wide, operational, multidisciplinary, in situ observing system. Satellite remote sensing provides a unique synoptic view of phenomena such

Published by Copernicus Publications on behalf of the European Geosciences Union. 


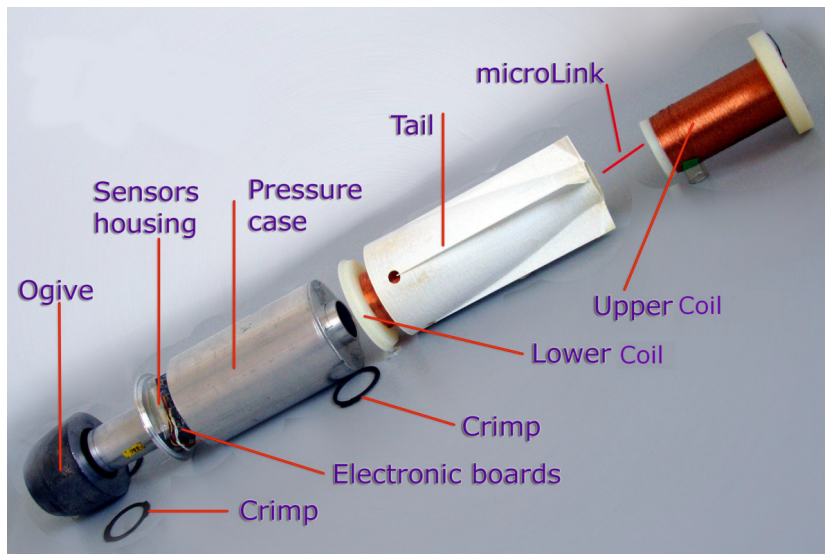

Fig. 1. The new probe components.

as chlorophyll concentration and sea surface temperature, but the measurement validation requires constant scrutiny and much sea-truth data as possible; for this reason the integration between field sampling and remote sensing technique should be improved also for the development of ecosystem model forecasts.

The estimation of primary production in the euphotic zone through remote sensing has been based mostly on visibleband water-leaving radiance measured with the coastal zone colour scanner. There are some robust, simple relationships for calculating integral production based on surface measurements, but they also require knowledge of photo adaptive parameters such as maximum photosynthesis which currently cannot be obtained from space (Balch and Byrne, 1994).

There is no way to quantify model performance without comparing the output to in situ data. When asked what is needed to improve model performance, all model developers coincide in requesting more data, ideally together with ancillary data such as nutrients and community structure (Carr et al., 2005)

More than for the physical variables, the biological ones have to be observed in situ. Especially in the mid-low latitudes, a deep observation of the water column is needed, because of the typical distribution of phytoplankton's biomass (Mann and Lazier, 1991).

The new probe presented in this work was charted in order to answer to the claim of a cost effective temperature and fluorescence expendable profiler, to be used in ships of opportunity. Its development, born inside the MFS-TEP-VOS, had the aim to add biological profiling measurements to the physical ones, in order to have more extensive information on chlorophyll concentration in the sea. Chlorophyll is an index of phytoplankton's biomass, and is also the most common property that characterizes marine productivity.

The possibility of using a continuous profiling probe, with an active fluorescence measurement, is very important in the study of phytoplankton in real time; it is the best way to fol-

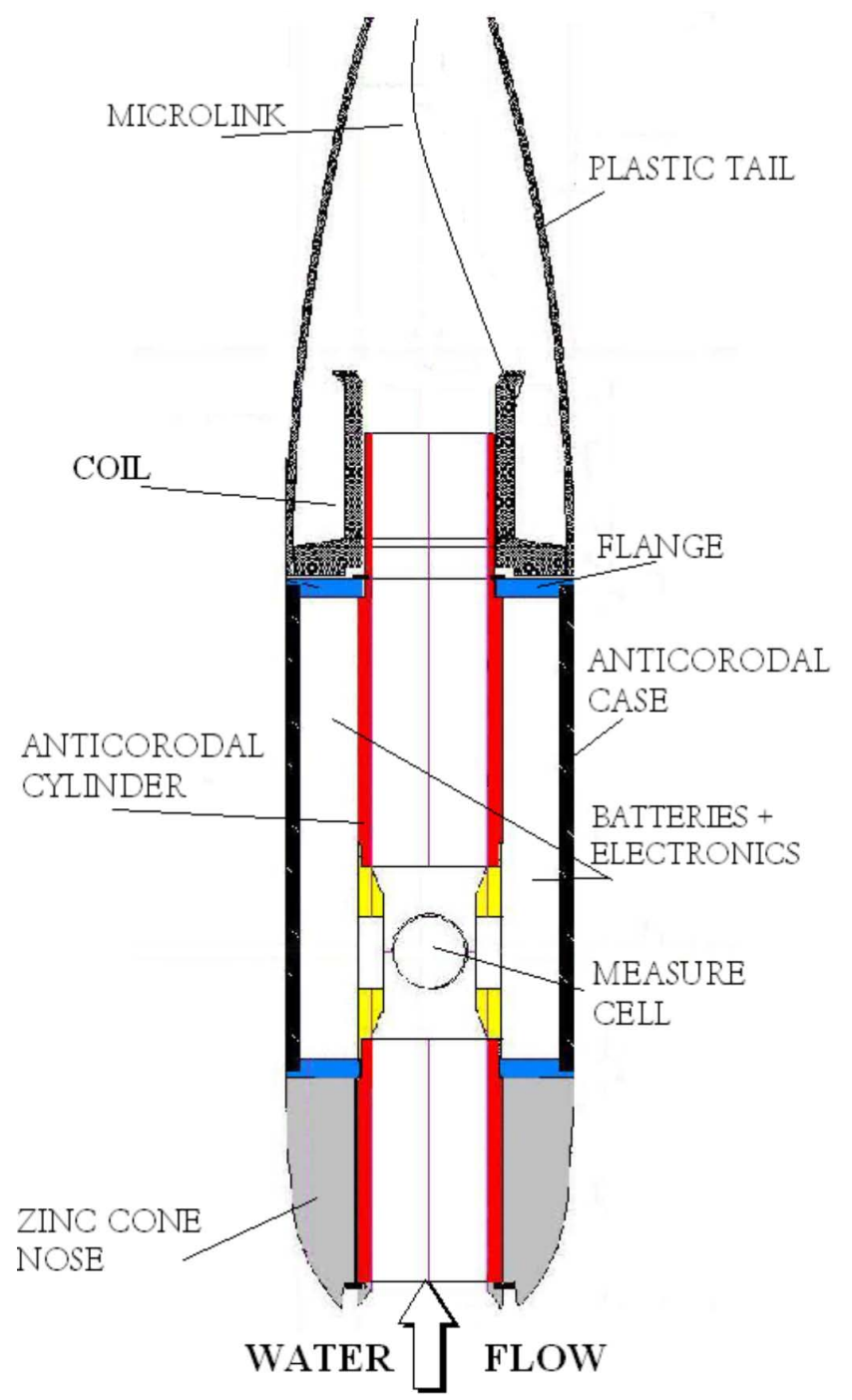

Fig. 2. Schematic functioning of the probe. The water enters the measurement cell were temperature and fluorescence measurements take place.

low the variability of sea productivity. In fact, because of the high time and space variability of phytoplankton, due to its capability to answer in a relatively short time to ecological variations in its environment (Lewis et al., 1984) and because of its characteristic patched distribution, there isn't a precise quantitative estimation of the biomass present in the Mediterranean sea. Moreover primary producers in the sea, phytoplankton at first, contribute for the $40 \%$ of global assimilation of inorganic carbon (Falkowski et al., 2002), resulting particularly relevant in the study of global change.

The development of the expendable fluorometer has followed similar concepts of the XBT (a wire conducting the signal to a computer card), but differently from the latter it was developed with an electronic system which can be improved and adapted to several variables measure channels. 
Commercial components were used for the development of a prototype, with the aim of a low-cost probe: a glass bulb temperature resistor for the temperature measurement, blue LEDs, a photodiode and commercial selective glass filters for the fluorescence measurement. The measurement principle for the detection of phytoplankton's biomass is the active fluorescence, which enables to have an in vivo chlorophyll estimation, measuring the immediate biophysical reaction of the phytoplankton inside the aquatic environment (Lorenzen, 1966). This is a non-disruptive method which gives real time estimation and avoids the implicit errors due to the manipulation of samples.

\section{Instrument and method}

This expendable probe can estimate the Chlorophyll "a" fluorescence and water temperature until a depth of $350 \mathrm{~m}$. It has a transmission system and a shape developed in order to allow its use from moving ships. The simplicity in the use of this probe and its relatively low cost were the basic requirements of the development. Other requirements were concerning the need to detect the deep chlorophyll maximum (DCM) with a sufficient accuracy, and temperature with an accuracy of $0.1^{\circ} \mathrm{C}$.

Electronics and firmware, for sensors management and data transmission, are placed inside the probe. Measurements take place in an internal cell, where the water flows while the probe descends along the water column. The data transmission is allowed by a twin copper wire wrapped on a coil placed in the tail of the probe and in a canister.

Architecture of the probe:

- A measurement cell represented by an anticorodal aluminium tube where the water flows in the inside; in the internal part of the tube are fixed the sensors which are in direct touch with the water, while on the external part of the tube are placed the batteries and the electronics.

- This central body is covered by a larger anticorodal aluminium tube, closed by two flanges, constituting the case where are placed batteries and electronics.

- On the tail is placed a coil with the copper wire for data transmission. The tail has a hydrodynamic shape that facilitates the wire unreeling.

- The frontal part is composed by heavy material to allow a vertical fall: it is constituted by a turned zinc ogive blocked by a metallic nail.

The main components of the probe are shown in Fig. 1, while a design of the longitudinal section is shown in Fig. 2.

The electronics are placed on two parallel faces of the measure cell. It is composed by two printed circuits and batteries (Fig. 3). These circuits contain the integrated electronic functions distinct for typology:

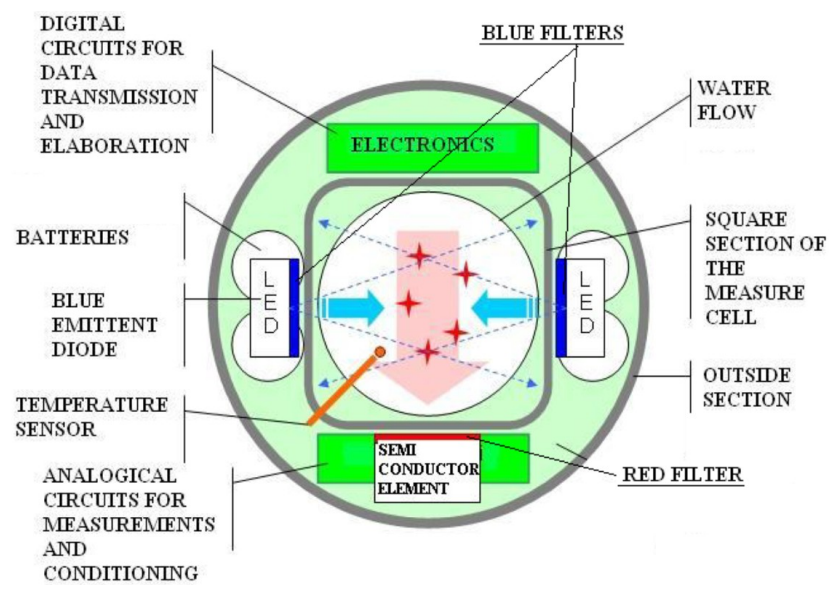

Fig. 3. A schematic section of the measurement cell.

- Circuit 1, positioned at the photodiode side, has all the analogical measure functions, signals conditioning and digital conversion functions.

- Circuit 2, has all the digital elaboration circuits, data transmission, LED diodes piloting functions and the power supply system.

The optimal shape-structure is $8 \mathrm{~cm}$ diameter for a $35.9 \mathrm{~cm}$ length. These dimensions assure a good weight distribution and, as a consequence, a good vertical lowering of the probe. The zinc ogive can be more or less heavy bringing to a total weight in water from $1.50 \mathrm{Kg}$ to $2.15 \mathrm{Kg}$.

\section{Sensors}

\subsection{Fluorometer}

The fluorometer is composed by:

- a source of light in the wavelengths of $430 \mathrm{~nm}, 450 \mathrm{~nm}$ $470 \mathrm{~nm}$ (blue LEDs)

- an optical filter which selects the blue wavelength from 430 to $480 \mathrm{~nm}$

- an amplified semiconductor element (with electronics integrated) as sensitive receptor

- an optical filter which selects the red light up to $600 \mathrm{~nm}$

\subsection{Temperature measurement}

The temperature measurement is effectuated through a glass bulb micro sensor which comes out from

the measure cell for $10 \mathrm{~mm}$ (Fig. 4), the sensitive part is composed by resistive sensor inside a spherical glass bulb with the diameter of $1.5 \mathrm{~mm}$. This sensor has a high sensitivity to temperature variations $\left(0.01^{\circ} \mathrm{C}\right)$ and to the dynamic variations $(0.05 \mathrm{~ms})$. 


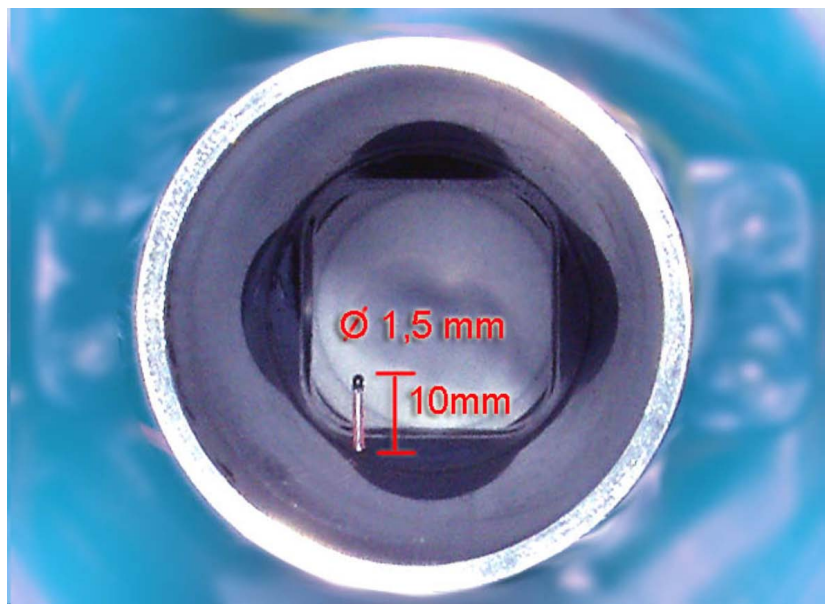

Fig. 4. The temperature sensor inside the measurement cell.

\subsection{Pressure measurement}

Depth was measured through a submersible pressure transducer (Keller).

The pressure transducer was inserted only on the first two prototypes used in the development phase.

\section{Digital transmission systems}

Data transmission is digital and is allowed by a twin copper wire ( $\mu$ link) wrapped on two separate coils; one of these is mobile and positioned in the tail, while the other is fixed in the canister launcher, through which the probe is connected to the pc on board.

Data acquisition doesn't need specific software, it is enough to have a pc terminal as Windows ${ }^{\circledR}$ HyperTerminal and follow the information transmitted by the connected device. The interactive menu allows different work activities including programming and controlling.

\subsection{Coil's capacity}

The mobile coil, inside the probe, has to contain a wire with a length as the maximum depth it could reach plus a tolerance length: the pre-serie has $700 \mathrm{~m}$ wire.

\subsection{Limits}

The application for which the expendable probe was designed is the profiling measure of fluorescence and temperature along the water column until a depth of at least $350 \mathrm{~m}$; being subjected to a progressive hydrostatic pressure, the functional limits of the instrument, concerning to the implosion of the materials, stand by $500 \mathrm{dBar}$, expecting this to be the highest pressure we need to reach.

A second limit is the capability of the coils to host a longer or thicker couple of conductors: for each one it was pre-

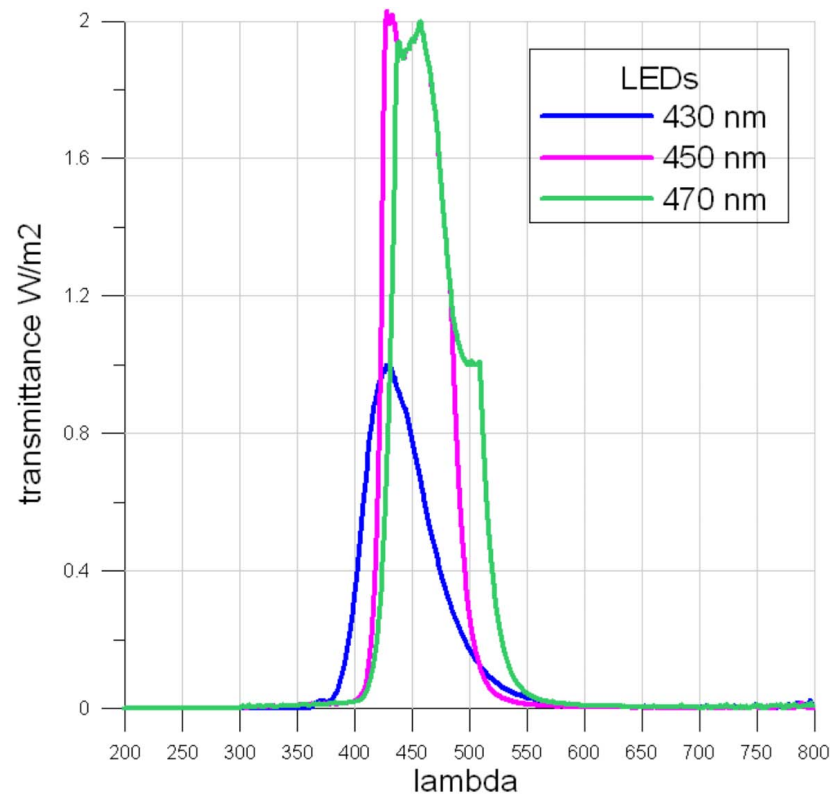

Fig. 5. Selected LED's transmittance $\left(w / \mathrm{m}^{2}\right)$ respect to wavelength (nm).

vented at the most a double length with the same diameter, or a bigger diameter with the present length.

\section{Development and optimization}

The development of the probe has followed two main phases.

\section{$5.1 \quad$ First phase}

The first phase of the experimental activities for the fluorometer assembly has been directed to an accurate evaluation of any element which was able to full fit the characteristics of the instrument's components (LEDs, diodes, filters), with particular attention to low cost components. The experimental study had the aim to find the best combination of the selected elements.

The spectral characteristics of different LEDs lights were analysed to detect the eventual presence of emissions in the red band, which would interfere with the chlorophyll measure. Afterward it was verified the transmittance of the filters and it was analysed the spectral emission of the LED with blue and red filters.

The analysis of LEDs spectra and filters transmittance was done with an EPP2000C UV+VIS Spectrometer (Wavelength Range $200-850 \mathrm{~nm}$; resolution $0.75 \mathrm{~nm}$ ). Once found the best transmittances, selected LEDs, combined with the selected filters, have been tested in the laboratory of Experimental Oceanology and Marine Ecology in Civitavecchia Italy. 


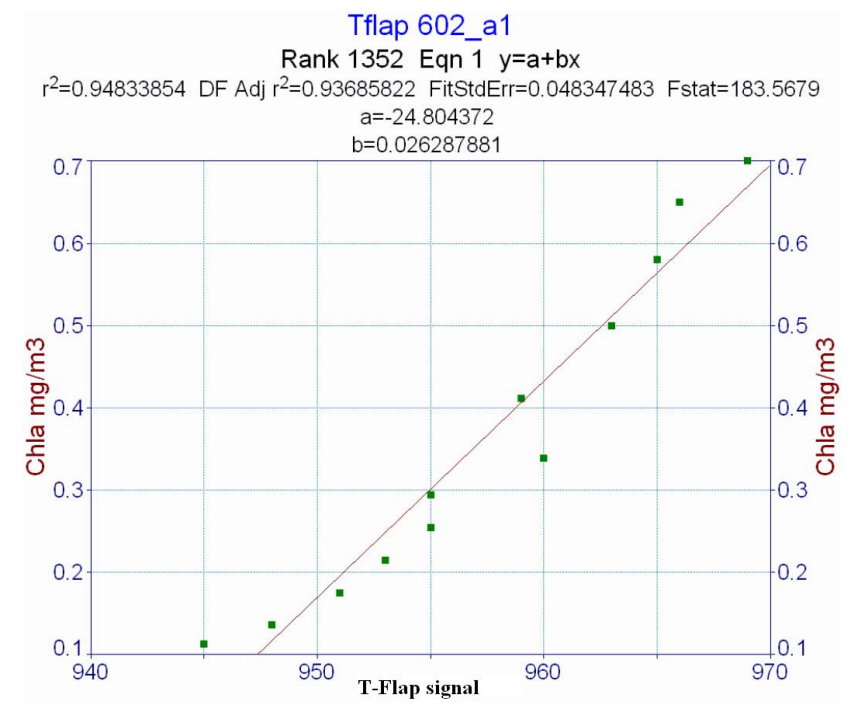

Fig. 6. On $\mathrm{x}$-axis there is the $\mathrm{Chl}$ "a" measured by the new probe $(\mathrm{mV})$ while on y there is the $\mathrm{Chl}$ " $\mathrm{a}$ " estimated by PrimProd 1.08 expressed in $\mathrm{mg} / \mathrm{m}^{3}$.

In Fig. 5 is shown the transmittance respect to the wavelength of the chosen LED diodes.

LEDs, filters and photodiodes were assembled in a not submersible measurement cell. By using an oscilloscope, the photodiode output signal was measured to detect the "parasite" light (deduced from the noise signal).

Different filters were analysed such as acetylene filters used for a first prototype (LEEfilters) and glass photographic coloured ones. Once verified that there was no appreciable interference from glass on light emission, we had reason to utilize it as support for the filters. A final choice of the filters was operated in favour of photographic ones, in order to have retrievable and cheap components.

When the definitive geometry of the measure cell was defined, fluorescence measurements were carried in order to study the sensor's output signal and define its amplification. After each modification at the fluorometer, the quality of the output data was tested with different concentrations of in vivo Chlorella sp. cultures, which were analysed otherwise with spectrophotometer method (Lazzara et al., 1990).

\subsection{Second phase}

On the basis of this preliminary experimentation, different prototypes were assembled and tested.

At first two retrievable prototypes were assembled, which enabled to carry out in situ tests, analysing the output signals and bringing the required modifications (on the gain and on the optics).

The first two retrievable prototypes have the measurement cell a little larger and are geometrically different from the definitive probe. Moreover these are provided with a pressure

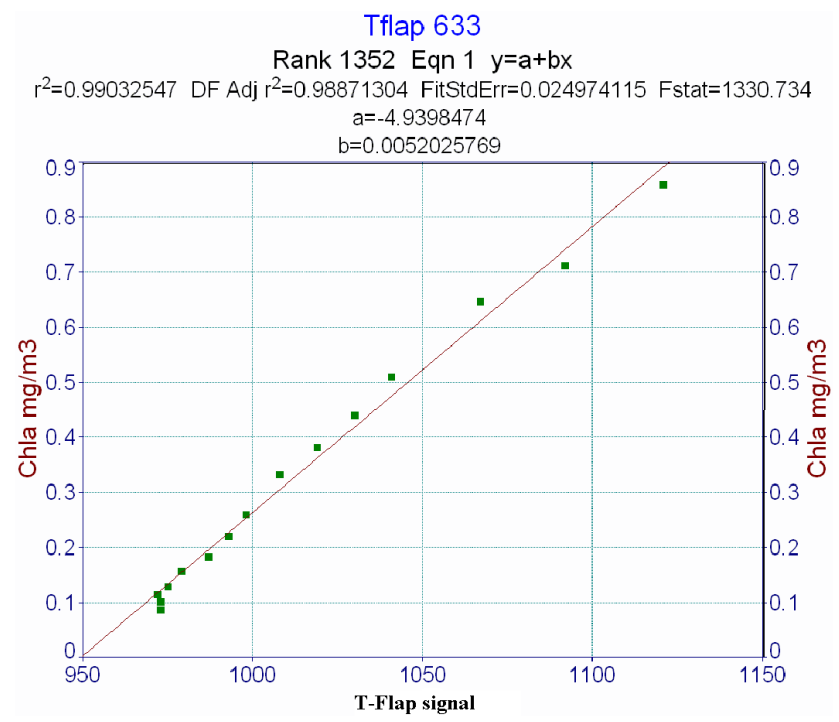

Fig. 7. Best Fit curve for the calibration of the new probe's fluorescence sensor: on $\mathrm{y}$ is reported the Chlorophyll concentration estimated by PrimProd $\left(\mathrm{mg} / \mathrm{m}^{3}\right)$ and on $\mathrm{x}$ is reported the signal given by the new probe's fluorescence sensor $(\mathrm{mV})$.

transducer that the expendable ones do not have, because of the need of a low cost instrument.

The study carried with the retrievable prototypes broth to the assemblage of the first 30 pre serie expendable probes.

\section{Fluorometer calibrations}

\subsection{Static calibration}

Different dilutions of a concentrate Chlorella sp. solution measured with a calibrated fluorometer (PrimpProd 1.08) were used for the static calibration of the new probe. PrimProd is a very sensible fluorometer, based on a photomultiplier sensible element developed by the Institute of Biophysics of Moscow (Antal et al., 2001).

The spectrophotometer analysis of the samples employed for the calibration of the fluorometer was made following the method reported by Lazzara et al. (1990).

In Fig. 6 is shown the relation between fluorescence measurements of the first prototype (number 602) and of the reference probe (PrimProd 1.08).

The Chlorophyll " $a$ " concentration range, used for the calibration of the fluorescence measurement (which regression curves are shown in Figs. 6 and 7) goes from $0.08 \mathrm{mg} / \mathrm{m}^{3}$ to $0.9 \mathrm{mg} / \mathrm{m}^{3}$ : The reason for choosing this range is the grater difficulty of the tested probe to detect the small Chlorophyll concentrations, while for the higher ones (the tests were leaded reaching at most $2 \mathrm{mg} / \mathrm{m}^{3}$ ) there is a good linear relation between the calibrated probe's signal and the real Chlorophyll "a" concentration. Moreover the Tyrrhenian sea, 


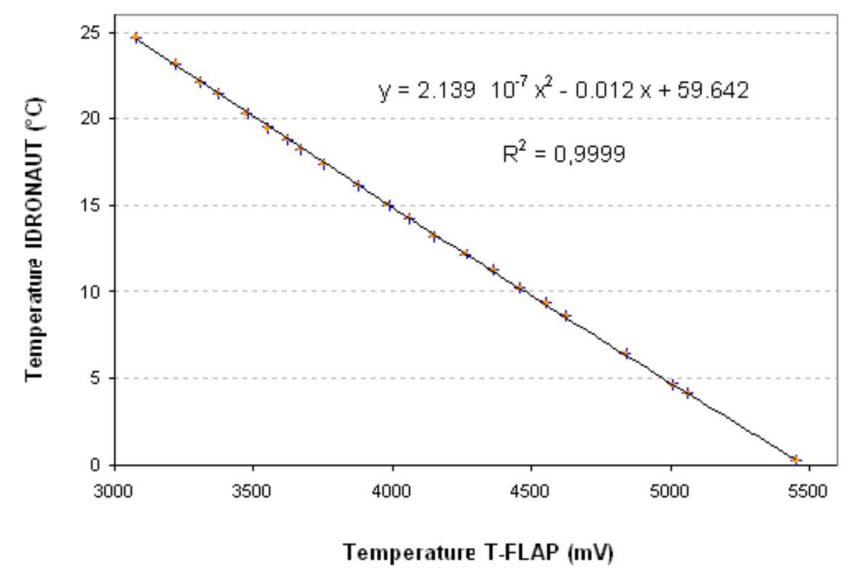

Fig. 8. On $x$-axis there is the temperature measured by new probe $(\mathrm{mV})$ while on $y$ there is the temperature measured by Idronaut 310 expressed in ${ }^{\circ} \mathrm{C}$.

where the probe was tested, is an oligotrophic system, where the mean biomass corresponds to a range of Chlorophyll "a" concentrations between 0.06 and $0.6 \mathrm{mg} / \mathrm{m}^{3}$ (Marcelli et al., 2005).

The first prototype, the retrievable one, has the measurement cell a little larger and geometrically different from the definitive probe, that's why in the calibration of the two types of probes (the retrievable and the expendable) there are differences in the regression coefficients.

\subsection{Dynamic calibration}

In order to acquire data simultaneously it was built a water flux circuit where the probes were inserted together with a reference fluorometer (PrimProd 1.11): the water flowed thanks to a bulk insulated tube system connected to a circulation/feeder pump (0.7 bar, 5.7 1/min) which kept a constant flow.

In this way it has been possible to effectuate a dynamic calibration, which is necessary to test an instrument that descends in the water column with a certain speed, letting the water flow inside of it.

In Fig. 7 is represented the best fit curve for the calibration of the fluorescence sensor of one of the pre serie expendable probes (number 633).

\subsection{Reference probe}

The reference probe, PrimProd 1.11, is a submersible PCcontrolled fluorometer (accuracy: $0.1 \mu \mathrm{g} / \mathrm{l}$ ) which uses the double flash "pump and probe" technique for measuring the constant and variable in vivo chlorophyll fluorescence, to estimate phytoplankton's abundance and the quantum efficiency of phytoplankton's photosynthesis, where a photomultiplier is the sensitive element (Piermattei et al., 2006).

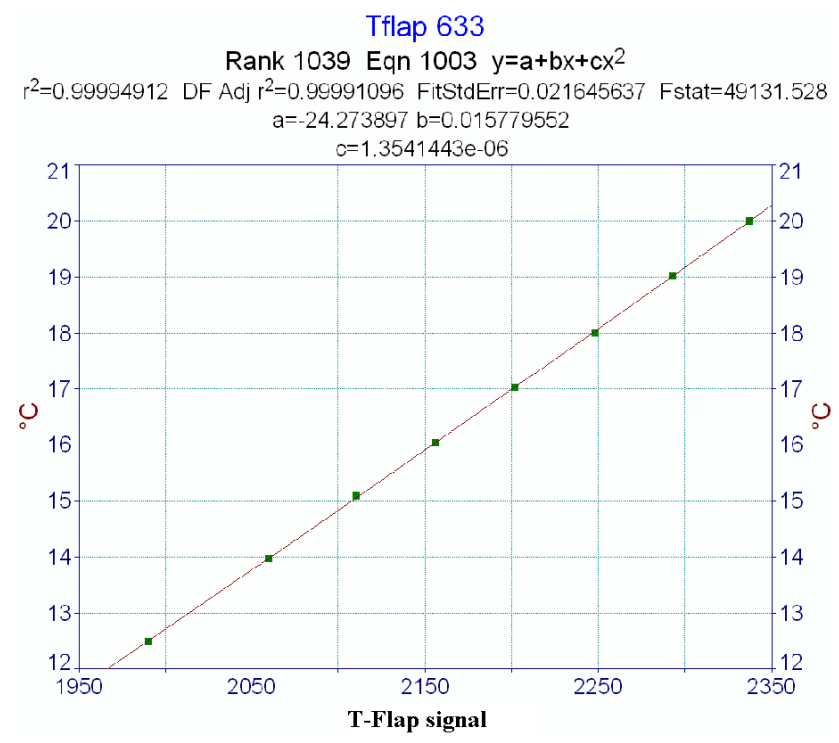

Fig. 9. Best Fit curve for the calibration of the temperature sensor: on $\mathrm{y}$ is reported the temperature measured by OTM Falmouth $\left({ }^{\circ} \mathrm{C}\right)$ and on $\mathrm{x}$ is reported the signal given by the new probe's temperature sensor $(\mathrm{mV})$.

\section{Temperature calibrations}

\subsection{Static calibration}

The response of the temperature resistor is converted in a tension signal value. To find out the conversion law, which allows transforming the $\mathrm{mV}$ signal value in ${ }^{\circ} \mathrm{C}$, the prototype was immerged in temperature controlled water and the degree temperature value has been obtained by a reference temperature sensor.

The temperature measurement inside the tub was done by means of an IDRONAUT 316 multi parametric probe which has got an accuracy of $0.003^{\circ} \mathrm{C}$.

For each of the 22 temperature values, correspondent voltage values were extracted from sensors and a regression analysis carried out (Fig. 8 shows the calibration curve for the retrievable prototype, n. 602).

\subsection{Dynamic calibration}

The temperature sensor was dynamically calibrated using the same flow system employed for the fluorescence calibration: this time the reference probe was a Falmouth OTM with Platinum Resistance Thermometer which has an accuracy of $0.003^{\circ} \mathrm{C}$.

In Fig. 9 is represented the best fit curve for the calibration of the temperature sensor of one of the pre serie expendable probes. 
CHLOROPHYLL a $\mathrm{mg} / \mathrm{m} 3$

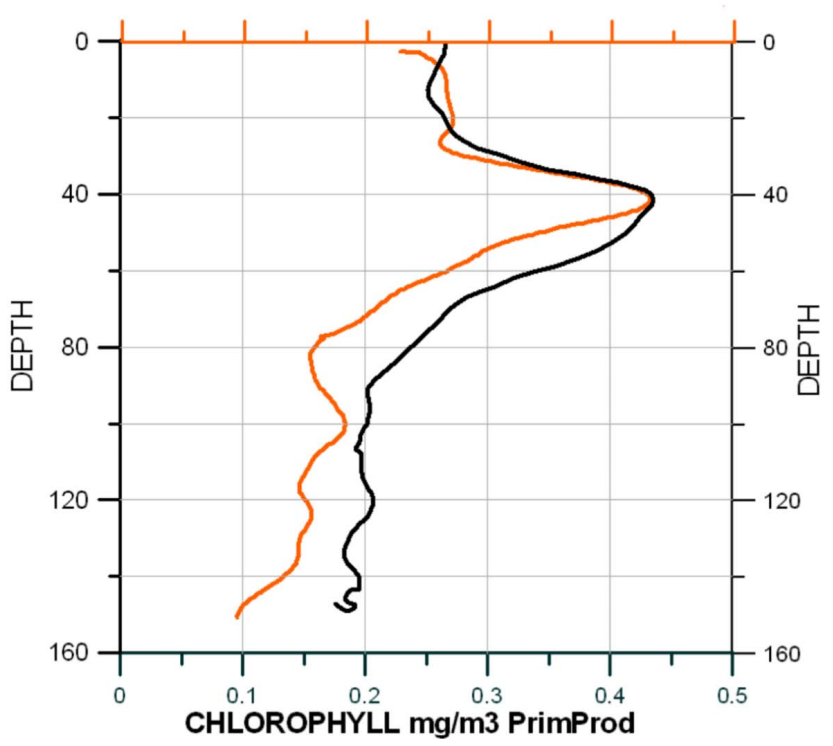

Fig. 10. St. $432: 37^{\circ} 43.62 \mathrm{~N}, 012^{\circ} 20.30 \mathrm{E}$, h 15:50 UTC. Fluorescence profile of the retrievable prototype (n. 602, orange line) compared to the reference measurements (Seatec, black line).

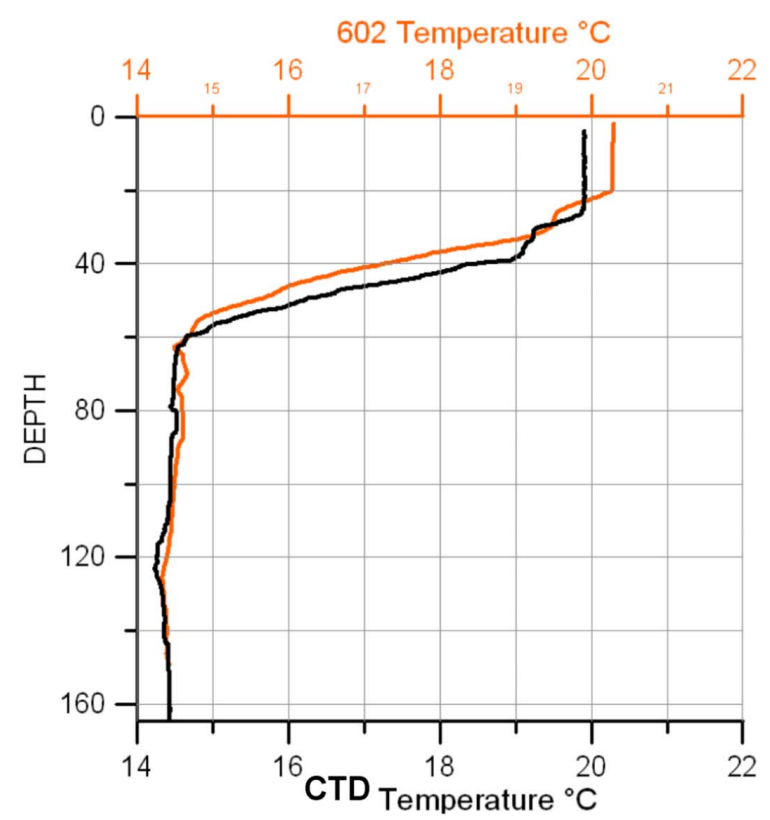

Fig. 11. St. 432 : $37^{\circ} 43.62 \mathrm{~N}, 012^{\circ} 20.30 \mathrm{E}$, h 15:50 UTC. Temperature profile of the retrievable prototype (n. 602, orange line) compared to the reference measurement (Seabird 911, black line).

\section{Field tests}

Field tests with the first retrievable prototypes were carried out on November 2005 during MedGOOS11 Cruise from the Urania R/V in the southern Tyrrhenian Sea.

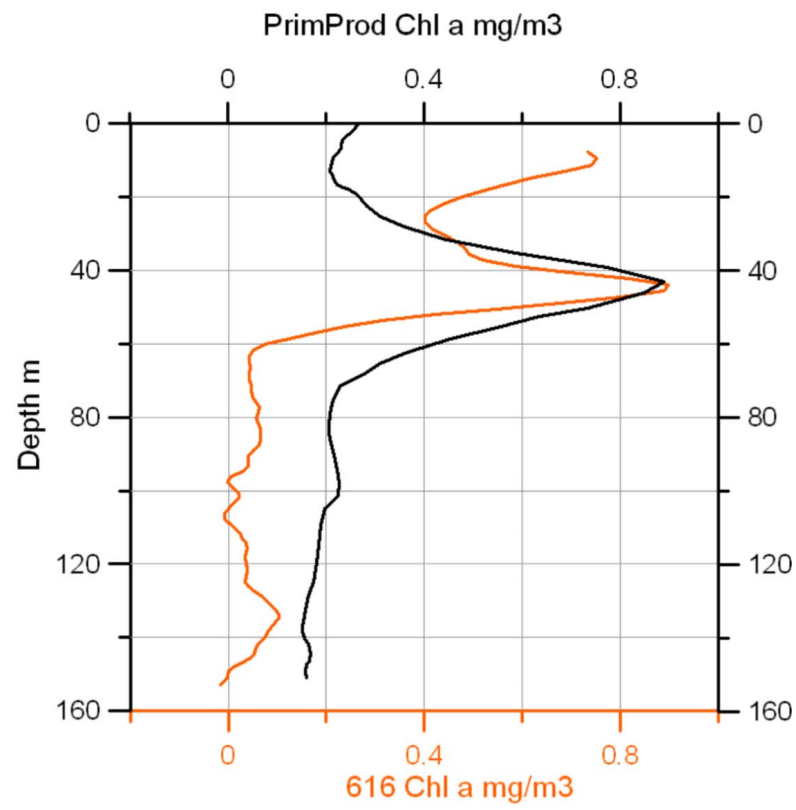

Fig. 12. Fluorescence profiles acquired on 24 April 2006 (h 12:00, $42^{\circ} 03^{\prime} 10.03^{\prime \prime} ; 11^{\circ} 45^{\prime} 54.89^{\prime \prime}$ ) by expendable prototype n. 616 (orange line) compared to Primprod 1.11 (black line).

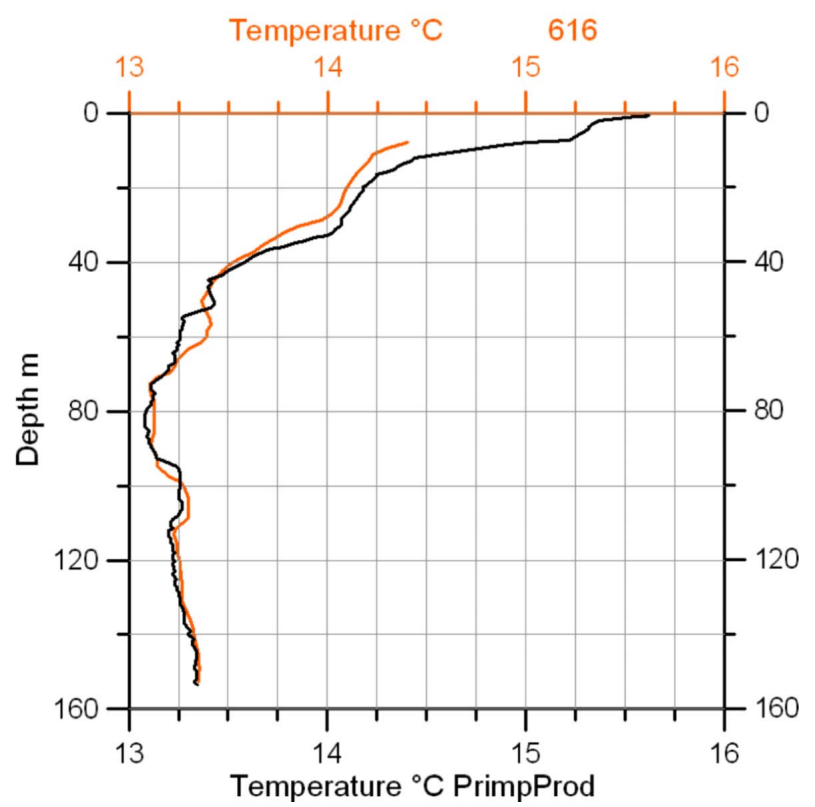

Fig. 13. Temperature profiles acquired on 24 April 2006 (h 12:00 $42^{\circ} 03^{\prime} 10.03^{\prime \prime} ; 11^{\circ} 45^{\prime} 54.89^{\prime \prime}$ ) by expendable prototype n. 616 (orange line) compared to Primprod 1.11 (black line).

The reference probes utilized for fluorescence and temperature measurements were: a Seatec Fluorometer and Seabird 911.

In Figs. 10 and 11 are shown a fluorescence and a temperature profile of a retrievable prototype (n. 602) compared 


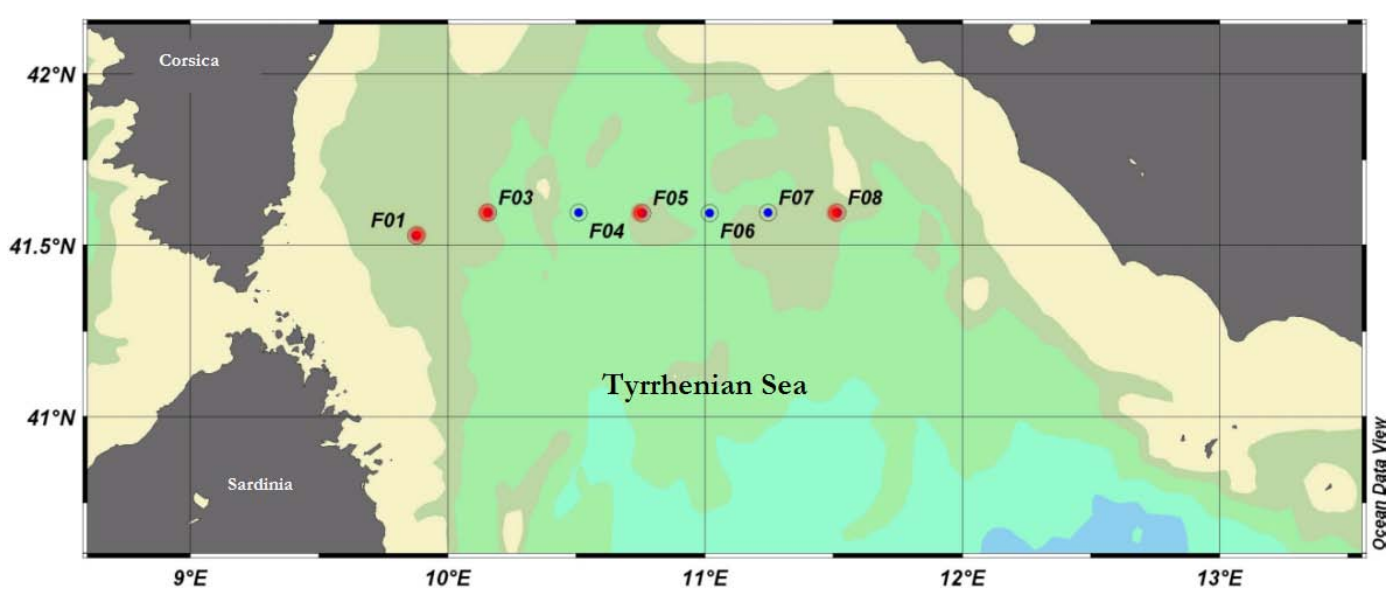

Fig. 14. Transect effectuated during MedGOOS13 on November 2006. The red spots correspond to the stations where four of the expendable prototypes were launched. The profiles in Figs. 15, 16, 17, 18 are referred to St. F01 (41 35.70 N, 009 59.54 E, h 17:42).

to the reference measurements (St. 432: $37^{\circ} 43.62 \mathrm{~N}$, 012⒛30 E, h 15:50 UTC).

The water in this period is still warm in the upper layer; it is appreciable the resolution of the thermocline and the fluorescence measure can successfully describe Chlorophyll "a" distribution in the water column. Similar results were obtained in all the field tests where the Deep Chlorophyll Maximum is clearly discerned.

It is appreciable a discrepancy between Primprod's (1.08), CTD's and tested probe's profiles.

In both graphs (Figs. 10 and 11) the chlorophyll and temperature profiles of the prototype don't follow the calibrated probe ones: the discrepancy is probably due to an imprecise calibration especially for the prototypes pressure sensor.

The first 30 prototypes of the expendable temperature fluorometers were launched mainly to verify the instrument capability to measure fluorescence when subjected to a falling speed such as 3-4 m/s.

Field tests with the pre serie expendable probes were carried out offshore Civitavecchia (Tyrrhenian Sea) on April 2006, from Sampei boat (the Tuscia University boat).

Fluorescence and temperature were measured by PrimProd 1.11.

In Figs. 12 and 13 there are represented the profiles obtained on April 2006 ( $42^{\circ} 03^{\prime} 10.03^{\prime \prime} ; 11^{\circ} 45^{\prime} 54.89^{\prime \prime}$ h 12:00) by the expendable prototype n. 616 compared to Primprod 1.11: we can newly see that the thermocline and the DCM are clearly discerned.

The discrepancy that we can see in the first meters is due to a saturation effect on the photodiode of the prototype, which disappears after a few seconds. The high falling speed in the first meters enhances the saturation phenomena which, even if takes place in the superficial layer, affects the signal until nearly $20 \mathrm{~m}$ of depth.
Under the DCM it becomes relevant the less sensitivity of the expendable prototype respect to the reference fluorometer.

As shown in Figs. 12 and 13 the expendable probe's profiles seem to be shifted respect to the reference ones: this must be due to the falling rate equation employed to find out the signals corresponding depth. The fall rate equation adopted to estimate the probe's falling speed was obtained from the studies referred to XBT (Reseghetti et al., 2006).

The equation adopted for the XBT is specific for a probe launched from an high of two meters while our prototype was left at the water surface: for XBT the falling rate diminishes along the water column before reaching a constant speed, while for our prototype (in this case) the velocity becomes greater before reaching a constant speed.

The last in situ tests were carried out during MedGOOS13 Cruise on November 2006 from the Urania R/V in the Tyrrhenian Sea (Fig. 14) with the pre serie expendable probes.

On the Urania R/V the reference measurements were obtained with CTD (equipped with Seabird 911 and Chelsea Fluorometer).

In Figs. 15, 16, 17, 18 are shown the profiles obtained on St. F01 ( $41^{\circ} 35.70 \mathrm{~N}, 009^{\circ} 59,54 \mathrm{E}$, h 17:42): Figs. 15 and 16 show respectively the fluorescence and temperature profiles obtained with the expendable prototype n. 623, while Figs. 17 and 18 represent respectively the fluorescence and temperature profiles obtained with Urania's CTD.

For the first meters the prototype was not able to discretize the signal: this must be due to the fact that the probe, launched from three meters, reaches a critical speed which does not permit the measurement.

The maximum of Chlorophyll detected by the prototype is near $0.4 \mathrm{mg} / \mathrm{m}^{3}$ while fro the Chelsea fluorometer is 


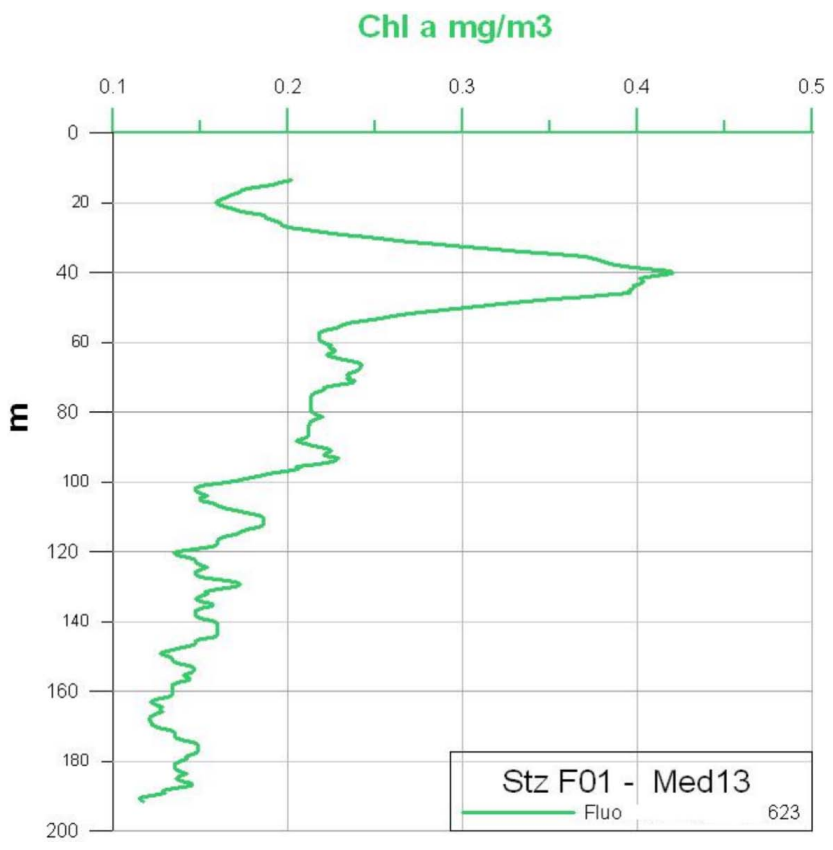

Fig. 15. Fluorescence profile obtained with the expendable prototype n. 623 on St. F01.

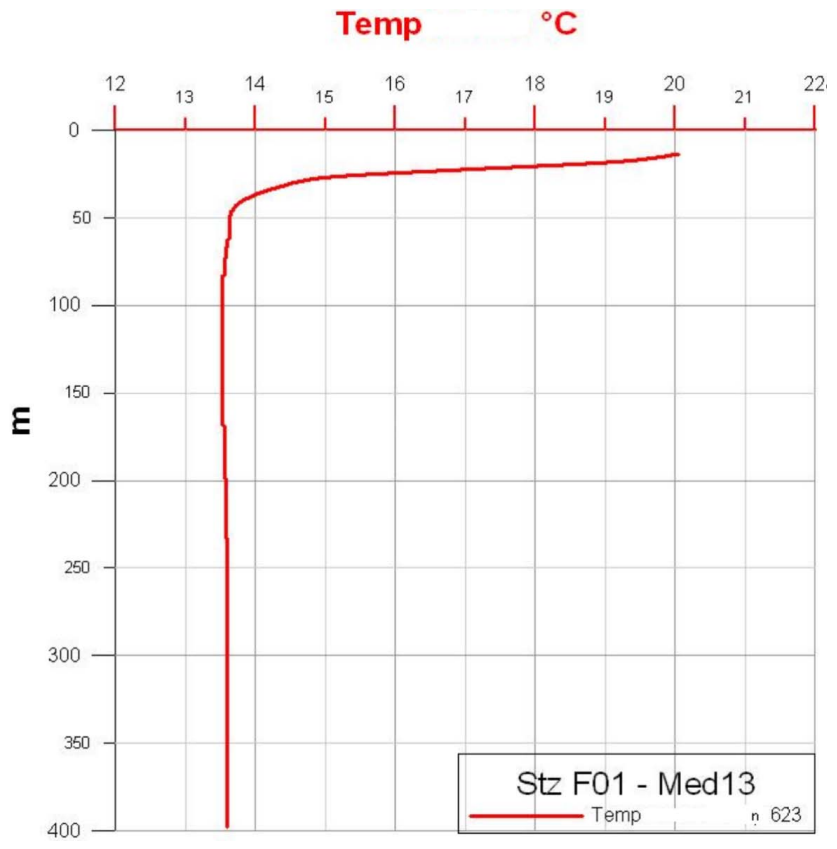

Fig. 16. Temperature profile obtained with the expendable prototype n. 623 on St. F01.

$0.25 \mathrm{mg} / \mathrm{m}^{3}$ : this is a quite big difference which can be explained by the different calibration of the two probes.

It is important to underline that the Tyrrhenian sea is the most oligotrophic area of the Mediterranean Western Basin, particularly in summer, with average $\mathrm{Chl}$ "a" concentrations
$\mathrm{Chl}$ a $\mathrm{mg} / \mathrm{m} 3$

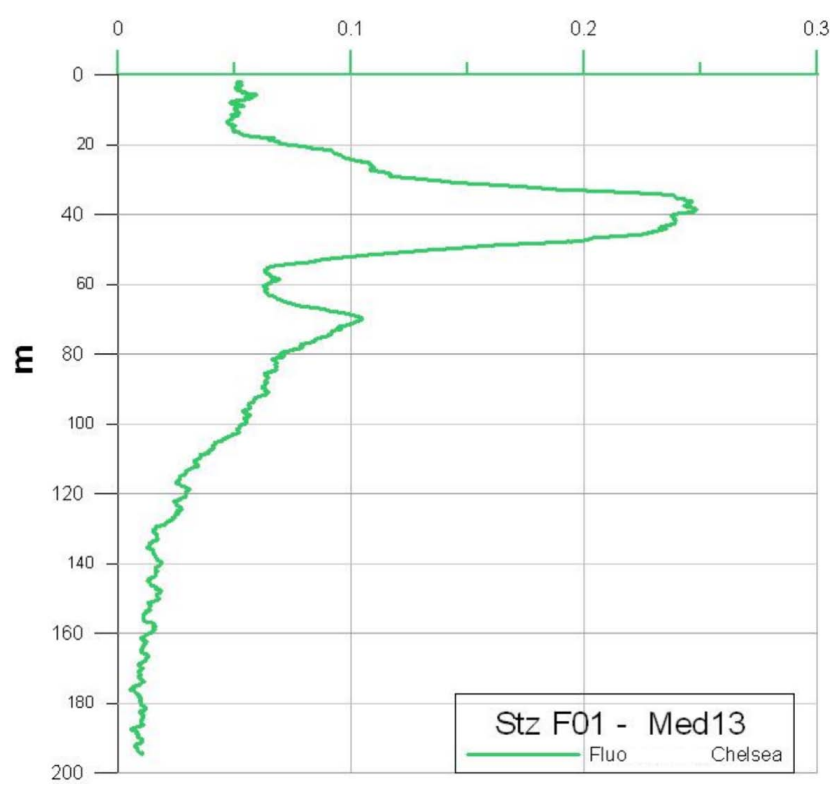

Fig. 17. Fluorescence profile obtained with Chelsea Fluorometer.

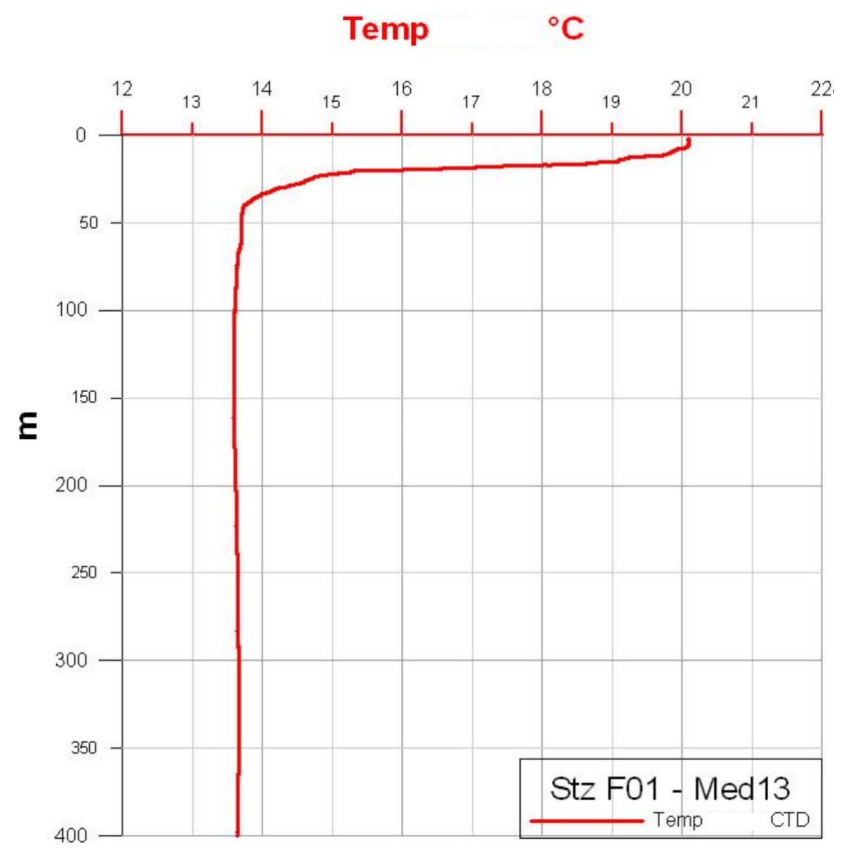

Fig. 18. Temperature profile obtained with Seabird 911.

by $0.06 \mathrm{mg} / \mathrm{m}^{3}$ in the upper layer (Bosc et al., 2004), while the DCM reaches $0.6 \mathrm{mg} / \mathrm{m}^{3}$ in late summer (Marcelli et al., 2005). 


\section{Conclusions}

The development of a new expendable probe for the measurement of temperature and fluorescence of Chlorophyll "a" has been based on system components having a low cost, available in commerce and purchasable by stocks in order to allow a massive production, as required by an expendable probe. Temperature measurements have reached the accuracy of $0.01^{\circ} \mathrm{C}$. The fluorescence measurement, even if the probe was tested in an oligotrophic sea, reaches an accuracy which satisfies the aim of a clear detection of the deep chlorophyll maximum: this ensures the description of phytoplankton's biomass in most of the seas which are more productive than the Tyrrhenian.

Acknowledgements. The development of the fluorometric expendable probe was done in the framework of MFS-TEP, a project supported by the EC under contract EVK3-CT-2002-00075.

The authors would like to thank: N. Pinardi, A. Cruzado, G. Coppini, V. Piermattei, I. Nardello, L. Lazzara, M. Mainardi, A. Anav, G. Zappalà and M. Scardi.

Edited by: N. Pinardi

\section{References}

Antal, T. K., Venediktov, P. S., Matorin, D. N., et al.: Measurements of phytoplankton photosynthesis rate using a pump and probe fluorometer, Oceanologia, 43, 291-313, 2001.

Balch, W. and Byrne, C. F.: Factors affecting the estimate of primary production from space, Geophys. Res. J., 99, 7555-7570, 1994.

Bosc, E., Bricaud, A., and Antoine, D.: Seasonal and interannual variability in algal biomass and primary production in the Mediterranean Sea as derived from 4 years of SeaWiFS observations, Global Biogeochemical Cycles, 18, GB1005, doi:10.1029/2003GB002034, 2004.
Carr, M.-E., Friedrichs, M. A. M., Schmeltz, M., Aité, M. N., Antoine, D., Arrigo, K. R., Asanuma, I., Aumont, O., Barber, R., Behrenfeld, M., Bidigare, R., Buitenhuis, E., Campbell, J., Ciotti, A., Dierssen, H., Dowell, M., Dunne, J., Esaias, W., Gentili, B., Groom, S., Hoepffner, N., Hishisaka, J., Kameda, T., LeQuéré, C., Lohrenz, S., Marra, J., Mélin, F., Moore, K., Morel, A., Reddy, T., Ryan, J., Scardi, M., Smyth T., Turpie, K., Tilstone, G., Waters, K., and Yamanaka, Y.: A comparison of global estimates of marine primary production from ocean colour, Deep-Sea Res., Part II, 53, 741-770, 2005.

Falkowski, P. G.: The ocean's invisible forest, Scientific American, 287, 38-45, 2002.

Lazzara, L., Bianchi, F., Falcucci, M., Modigh, M., and Ribera D’Alcalà, M.: Pigmenti Clorofilliani, Nova Thalassia, II, 207223, 1990.

Lewis, M. R., Cullen, J. J., and Platt, T.: Relationship between vertical mixing and phytoplankton: similarity criteria, Mar. Ecol. Prog. Ser, 15, 141-149, 1984.

Lorenzen, C. J.: A method for the continuous measurement of in vivo chlorophyll concentration, Deep-Sea Res., 13, 223-227, 1966.

Mann, K. H. and Lazier, J. R.: Dynamics of Marine Ecosystem, Blakwell Science, 1991.

Marcelli, M., Caburazzi, M., Perilli, A., Piermattei, V., and Fresi, E.: Deep Chlorophyll maximum distribution in the central Tyrrhenian Sea described by a towed ondulating vehicle, Chemistry and Ecology, 21, 351-367, 2005.

Piermattei, V., Bortoluzzi, G., Cozzi, S., Di Maio, A., and Marcelli, M.: Analysis of mesoscale productivity processes in the Adriatic sea: comparison between data acquired by SARAGO, a towed ondulating vehicle, and by CTD casts, Chemistry and Ecology, 22, supp. 1, S275-S292, 2006.

Pinardi, N., Allen, I., Demirov, E., De Mey, P., Korres, G., Lascaratos, A., La Traon, P.-Y., Millard, C., Manzella, G., and Tziavros, C.: The Mediterranean ocean Forecasting System, first phase of implementation (1998-2001), Ann. Geophys., 21, 320, 2003, http://www.ann-geophys.net/21/3/2003/.

Reseghetti, F., Borghini, M., and Manzella, G. M. R.: Factors affecting the quality of XBT data-results of analyses on profiles from western Mediterranean sea, Ocean. Sci., 3, 59-75, 2007. 